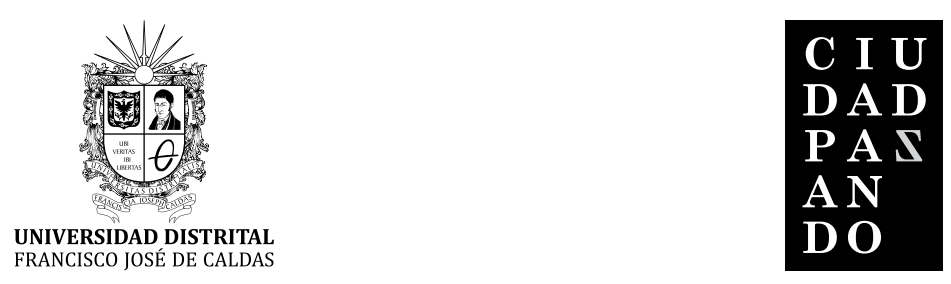

\title{
DOSSIER
}

Artículo de investigación científica

\section{Los riesgos y el papel político de las lideresas sociales en la construcción de la paz territorial en Colombia}

The risks and political role of female social leaders in territorial peace construction

Os riscos e o papel das mulheres líderes sociais na construção da paz territorial

\section{Sandra Milena Barreto Daza ${ }^{1}$}

Para citar este artículo: Barreto, S. (2018). Los riesgos y el papel político de las lideresas sociales en la construcción de la paz territorial en Colombia. Revista Ciudad Paz-ando, 11(1), pp. 7-15. doi: https://doi.org/10.14483/2422278X.13079

Fecha de recepción: 28 de febrero de 2018

Fecha de aprobación: 17 de abril de 2018

Magíster en Estudios Políticos e Internacionales, Universidad Colegio Mayor del Rosario, Colombia. Correo electrónico: psicosandra@gmail.com 


\section{RESUMEN}

Este artículo busca problematizar el papel político de las mujeres lideresas en la construcción de paz y los riesgos que enfrentan en la defensa de los Derechos Humanos; así, a lo largo del análisis se abordarán las relaciones de poder y los intereses que atraviesan los contextos donde trabajan estas mujeres. A través de entrevistas a dieciocho lideresas en Bogotá D.C, Cundinamarca, Sucre, Antioquia y Nariño, se logró determinar las causas sociales que las convocan y las trayectorias de persecución que han sufrido como una forma de retaliación hacia el activismo y los procesos liderados en sus comunidades. En general, estas mujeres han acompañado el sufrimiento de la guerra y han impulsado procesos de participación e incidencia política necesarios para la construcción de la Paz en sus territorios.

Palabras clave: conflicto armado colombiano, construcción de paz territorial, liderazgos sociales de las mujeres.

\section{ABSTRACT}

This article seeks to problematize the political role of female leaders in peace construction and the risks they face in the defense of Human Rights. This analysis approaches the power relations and interests that cross the contexts where these women work. Through interviews to 18 leaders in Bogotá D.C, Cundinamarca, Sucre, Antioquia y Nariño, it was possible to determine the social causes that motivate them and the prosecution trajectories that they have suffered as a way of retaliation to their activism and the led processes in their communities. In general, these women have accompanied the suffering of war and they have driven participation and political incidence processes, which are necessary for peace construction in their territories.

Keywords: armed conflict in Colombia, social leadership of women, territorial peace construction.
Este artigo procura problematizar o papel político das mulheres líderes na construção de paz y os riscos que enfrentam na defesa dos Direitos Humanos. Esta análise aborda as relações de poder y os interesses que atravessam os contextos onde elas trabalham. Através das entrevistas as $18 \mathrm{mul}-$ heres líderes em 4 estados regionais na Colômbia, logrou-se determinar as causas sociais que as convocam e as trajetórias de percussão que têm sofrido como uma maneira de retaliação contra seus ativismos e processos liderados em suas comunidades. Em geral, estas mulheres tinham acompanhado o sofrimento da guerra e tinham impulsado processos de participação e incidência política precisos para a construção da paz em seus territórios.

Palavras-chave: conflito armado em Colombia, construção de paz territorial, lideranças sociais das mulheres. 


\section{Introducción}

En Colombia fueron asesinados 73 líderes y lideresas sociales a lo largo de 2017 (ONU, 2017 citado en la Revista Semana, 2017), lo que permite afirmar que este es uno de los años de mayor violencia contra defensores de Derechos Humanos (DDHH); de hecho, las tasas de persecución violenta y los homicidios a líderes sociales en todo el país se han venido incrementando, ya que en los últimos cuatro años han sido asesinados alrededor de 300 líderes sociales y, en la última década, la cifra asciende a 500 líderes sociales asesinados en todo el país (ACNUDH, 2015; ACNUDH, 2016; Programa Somos Defensores, 2017).

Además de los homicidios, continuamente se registran denuncias de agresiones, estigmatización, amenazas, violencia sexual, desapariciones y desplazamientos forzados, lo que permite afirmar que en Colombia existen numerosos riesgos para el ejercicio del liderazgo social. Al respecto, es importante decir que pese a que se firmaron y se han venido implementando los Acuerdos de Paz con las Farc, los cuales contemplan el desarrollo de medidas de protección para el ejercicio de la participación política en Colombia, lamentablemente aún persiste la falta de garantías para la defensa de los DDHH en territorios que han sido marcados por la violencia.

No obstante, aunque las cifras de homicidios evidencian una mayor tasa de asesinatos a hombres que son líderes sociales —por ejemplo, en 2016 de las 80 personas asesinadas, nueve son mujeres (Programa Somos Defensores, 2017, citado en Barreto 2017)—, en distintos informes (SISMA Mujer, 2016) se señala que las lideresas sociales enfrentan riesgos particulares o riesgos de género, los cuales son formas de violencia vinculadas a las creencias y preceptos propios de un sistema cultural de tipo patriarcal, que en esencia configura unas relaciones de poder asimétricas entre lo masculino y lo femenino o un sistema social dominado por la figura masculina (Hernández, 2006; OIM, s.f.). En esa medida:

Estos parámetros han propiciado que las mujeres se vean enfrentadas a una serie de barreras que dificultan el ejercicio de la autonomía; barreras que en escenarios de guerra se convierten en una serie de violencias basadas en género las cuales se perpetúan sólo por el hecho de ser mujeres (OIM, s.f., citado en Barreto, 2017, p. 19).

Esto no quiere decir que los riesgos y las violencias basadas en género atenten de manera exclusiva a las mujeres, lo que aquí se pretende evidenciar, son las diferentes formas de discriminación preexistentes que limitan el goce efectivo de los derechos de las mujeres y claro, limitan sus ejercicios de participación.

Por consiguiente, las lideresas sociales se ven enfrentadas a diversos riesgos de género con ocasión del conflicto, como una forma de perseguirlas y castigarlas por ser mujeres que participan en la vida política, esto genera interrogantes sobre los riesgos, sobre los aportes de las mujeres a la construcción de la paz territorial.

Con este fin, a partir de las premisas del Modelo de análisis estratégico de Michael Crozier y Erhard Friedberg (1980), se reconstruirá todo el marco de las relaciones de poder que conducen a que las lideresas sociales tengan un potencial político en sus territorios y que sean determinantes en las decisiones que se asumen en el tejido comunitario; a su vez, este modelo permite dilucidar los intereses de los diferentes actores, pero sobretodo los dispositivos y juegos estructurales anclados a una cultura patriarcal, que privilegia la voz masculina en el ámbito público.

En general, los liderazgos sociales de las mujeres son considerados como distintas formas de acción política que tienen como objetivo acompañar e impulsar procesos de incidencia y participación de las comunidades y grupos de la sociedad civil (Montenegro, 2004). Desde este planteamiento, en el documento se plantea una interpretación del papel político de las lideresas sociales en la construcción de la paz territorial y, a la vez, se trazan las trayectorias de persecución violenta que sufren estas en el impulso de distintas causas sociales. Las reflexiones pretenden contribuir al debate sobre las medidas de política para la garantía de la defensa de los derechos humanos en Colombia, y para el caso las líneas de acción dispuestas para el ejercicio de los liderazgos sociales de las mujeres en territorios en los que históricamente se ha vivido el conflicto armado.

\section{Metodología}

En este artículo se retoma parte de los resultados de la investigación denominada: "Riesgos de los liderazgos sociales de las Mujeres en el contexto del conflicto armado colombiano: configuración de un problema de política pública" (Barreto, 2017), la cual busca hacer un análisis de política pública sobre el problema de las amenazas y los riesgos que enfrentan las lideresas sociales en Colombia.

Con una metodología de corte cualitativo, esta investigación se enfocó a la interpretación de las relaciones de poder y los intereses políticos desde las experiencias $\mathrm{y}$ trayectorias de vida de dieciocho lideresas sociales en cinco territorios a lo largo del país: Bogotá D.C, Cundinamarca, Antioquia, Sucre y Nariño.

Para ello, se realizaron cuatro grupos focales y cinco entrevistas semiestructuradas (realizadas en el primer semestre del 2016) en las que se abordaron temas relacionados con la participación política de las mujeres y los liderazgos sociales: las causas sociales, los espacios de incidencia política, la paz, los riesgos y las relaciones con actores presentes en el territorio. En este sentido, se enfatizó en las relaciones con los actores de gobierno, sus comunidades y los grupos armados ilegales, pues uno de los criterios de selección de las mujeres es que fueran lideresas que trabajaran en territorios de conflicto o que en algún momento hubiesen sufrido amenazas. 
Teniendo en cuenta que era díficil encontrar los casos de mujeres que hayan sido amenazadas con ocasión del conflicto armado, en la investigación se optó por un muestreo no probabilístico de bola de nieve, con el que se identifican los casos a través de referencias y conocidos; en este caso, algunas lideresas y funcionarios que conocía la investigadora en los cinco territorios fueron quienes referenciaron a las mujeres que participaron en esta investigación.

Asimismo, y dadas las condiciones de seguridad, en el consentimiento informado, se acordó usar seudónimos, mencionar el nombre de la región, más no el municipio de residencia y se asumieron medidas de protección propuestas por las mujeres y de acuerdo con su esquema de seguridad. De allí que, por ejemplo, ninguna de las entrevistas y grupos focales se realizaron en los lugares o sectores de residencia y de trabajo de las mujeres.

El análisis de la información de realiza desde las orientaciones del Enfoque Hermenéutico- Interpretativo, el cual busca la comprensión de las acciones a partir del reconocimiento y la reconstrucción de lo que estas significan en los contextos sociales donde se desarrollan. En este estudio se interpretaron las narrativas de las lideresas a través de una estrategia de análisis categorial usando la herramienta de trabajo Atlas-ti, software para análisis de datos cualitativos, gestión y creación de modelos, que permitió la triangulación de la información obtenida a través del trabajo de campo, los marcos conceptuales usados a lo largo del proceso de investigación y la reconstrucción de las historias de vida de las mujeres frente a su papel político y a los riesgos que deben enfrentar con ocasión del conflicto armado.

Cabe mencionar entonces que las categorías de análisis sobre las que se proyectaron todas las reflexiones a partir del papel político de las lideresas sociales en la construcción de la paz territorial y los riesgos que encaran en escenarios de violencia sociopolítica, parten en primera instancia de las relaciones de poder en territorios de conflicto armado, los liderazgos sociales y los riesgos de género.

\section{Los escenarios políticos donde trabajan las lideresas sociales}

...ni la ley, ni la militar ni nada sino la ley del conflicto
armado es la que conocemos nosotros alli, a mi ningún
Estado me ha ayudado. Que yo misma con otras muje-
res y yo me capacito yo soy capaz y yo puedo multipli-
car y replicar lo que yo veo, eso es lo que el Estado me
ayuda vaya capacitese y le cuente a su comunidad...
MaríaElena.Lideresa comunal.EntrevistaAntioquia

Si bien el conflicto armado ha adquirido otras facetas y connotaciones a través de la implementación del Acuerdo Final para la Terminación del Conflicto y la Construc- ción de una Paz Estable y Duradera firmado en noviembre de 2016, las condiciones de pobreza, exclusión y violencia sociopolítica en los territorios persisten a través de la presencia de distintos actores armados, al igual que las situaciones de corrupción e incluso la ausencia de programas y líneas de política pública que aporten a la transformación de las condiciones estructurales generadoras de la guerra en Colombia (Coordinación Colombia, Europa, Estados Unidos, 2017).

Un aspecto fundamental para comprender el papel de las lideresas sociales en la construcción de la paz y las situaciones de persecución que han sufrido, es la comprensión del contexto social y los factores políticos que atraviesan la labor de exigibilidad y el acompañamiento comunitario que desempeñan estas mujeres en sus territorios. Tal como refiere María Elena, la ley del conflicto armado y las distintas formas de violencia sociopolítica siguen siendo parte de la cotidianidad de estos territorios, donde se persiguen ideologías y formas de construir sociedad que no correspondan con los patrones hegemónicos de los actores armados.

El conflicto armado en Colombia se constituye como una dinámica multifactorial que no solamente puede atribuirse a causas políticas (Comisión Histórica del Conflicto y sus Víctimas, 2015); no obstante, para esta investigación han cobrado importancia los factores que dan lugar al conflicto amado en términos de la inestabilidad e ineficiencia en el ámbito de gobernabilidad democrática (Torrijos, 2009; Pizarro, 2004), ya que precisamente lo que evidencia las amenazas, los homicidios y las violencias que han sufrido líderes sociales, indistintamente del género, es la incapacidad de las figuras y actores de gobierno para proveer protección y crear condiciones de garantías para la defensa de los DDHH en los territorios.

La gobernabilidad alude a las condiciones necesarias para administrar y presidir desde la concertación, el consenso y el mantenimiento del orden entre múltiples factores que afectan a las sociedades (Hague, Harrop y Breslin, 1998 citados en Torrijos, 2009). La gobernabilidad se puede identificar cuando, desde las figuras e instituciones de un Estado democrático, se definen y se hacen cumplir las leyes a través de autoridades electas (Pizarro, 2004).

La realidad de los territorios que han vivido el conflicto armado dista bastante de lo que se considera armonioso en términos de la gobernabilidad democrática, pues muchas veces la autoridad reposa en grupos armados ilegales que imponen su patrones e ideologías a través de las armas (Pizarro, 2004). Por eso, a lo largo de la investigación constantemente las lideresas sociales se referian a esta situación aludiendo a que el gobierno no proveía protección: "Se sentía una impotencia, yo sentía como unas ganas de llorar de pensar: ¿quién nos protege aquí? quien nos protege a nosotros? ..." (Lideresa comunal y de organizaciones sociales de mujeres. Grupo focal Antioquia). 
Ahora, podría decirse que el poder (en menor escala) también está concentrado en los líderes sociales quienes denuncian los problemas y situaciones de violencia, además de organizar a las comunidades en torno a distintas causas sociales y ser capaces de influenciar sus decisiones y acciones políticas:

Bueno, yo digo que como hemos aportado políticamente en la comunidad sobre todo con los votos, a decirles a muchas personas porqué votar, atreverse uno a decir: mire votemos por fulano, por este o por esta, por las cualidades de estas personas; mire quiénes son las que han participado acá en el barrio, quiénes han gestionado (Adelaida. Lideresa comunal. Grupo focal Antioquia).

Bajo esta lógica, las lideresas orientan a sus comunidades frente al quehacer de la política y, a la vez, cumplen un papel de cuestionamiento constante, no solo de la incapacidad del Gobierno por propiciar las bases de un Estado social de derecho, sino como se verá más adelante, también logran cuestionar al orden instaurado por los actores armados.

Lo cierto es que, ante la débil gobernabilidad, se afecta considerablemente la identidad democrática de las comunidades o el grado de interiorización del régimen político democrático (Torrijos, 2009), pues la gente vive en medio del miedo y la desesperanza, ya que muchas veces las figuras institucionales del Estado no son quienes les garantizan protección y en zonas rurales, sobretodo, el vacío democrático genera que se instalen regímenes a modo de Estado local (Pizarro, 2004), donde el poder y la autoridad del Estado ha sido sustituida por actores o grupos armados ilegales.

Podría decirse, entonces, que uno de los aportes de las lideresas a la construcción de la paz territorial tiene que ver con la reconstrucción de la identidad democrática y de la confianza, pues a través del activismo, la movilización y la formación a las comunidades en discursos democráticos como los DDHH, las lideresas orientan, acompañan el miedo y, en muchos casos como María Elena expone a continuación, ocupan lugares de autoridad y del ejercicio de la democracia, por eso fueron perseguidas por los actores armados:

He concursado en la junta administrativa local, salía de los tres años, jui la primera edil de la comunidad de mi corregimiento y para qué! Siempre me ha gustado la política, aprendí a buscar a muchas mujeres a decirles que la política es buena pero siempre hay que estudiar y vienen mujeres muy preparadas... pero después no me dejaron los paramilitares porque yo quería ser concejal (María Elena. Lideresa comunal. Entrevista Antioquia).

Lo anterior tiene dos connotaciones: la primera, es necesario evidenciar el papel específico de las mujeres lideresas sociales en la reconfiguración y estabilización de los procesos democráticos y, por supuesto, en las apuestas de construcción de paz territorial; por otro lado, evidenciar cómo este papel de alguna manera incómoda a los actores sociales que las persiguen, las amenazan y las violentan para seguir ocupando lugares de poder en los territorios.

\section{Las causas sociales lideradas por las mujeres para la construcción de paz}

Como se mencionaba, las mujeres lideresas cumplen un papel específico en el acompañamiento de las comunidades y la transformación de las condiciones estructurales asociadas a la violencia social y política; por consiguiente, abordar este rol permite no solamente entender los alcances que han tenido, sino también reconstruir nociones sobre la persecución política que han enfrentado - como las amenazas y los señalamientos por ser mujeres que participan en la vida política de sus regiones-, lo que en definitiva se constituye como uno de los principales obstáculos para la construcción de la paz territorial.

En general, en la gran mayoría de las mujeres se identifican largas trayectorias de liderazgo, un gran conocimiento de las leyes, la estructura del Estado y la forma como se puede incidir en asuntos de política pública. Este es un factor que evidentemente las ubica en una posición de poder, pues las comunidades las consultan para tomar decisiones o para ser orientadas en rutas de garantías de derechos. A esto hace alusión Tomasita, sobre el potencial y los rasgos particulares de las lideresas sociales:

Porque yo no conocía, ni siquiera me había atrevido a declarar. Pero a mis oídos sí llegaban buenos comentarios de positivismo y de la gestión que ella hacía. Que es una mujer de gestión, una mujer que buscaba, con altos conocimientos. De liderazgo. Una mujer que tiene conocimientos, esta mujer no se deja embolatar. Esa mujer no es abogada, pero se sabe los artículos (ríe), desde la ley, los derechos. Conoce la ley, que nadie la embolataba (Tomasita. lideresa social de mujeres víctimas del conflicto armado. Grupo focal Sucre).

De igual forma, en las dieciocho mujeres entrevistadas fue evidente que las historias de violencia, las condiciones de pobreza e incluso formas de violencias basadas en género, se constituyen como el principal motor para que quieran liderar procesos de empoderamiento comunitario, así como lo explica Fanny en su relato:

Bueno, es que es de niña, uno empieza ver las injusticias y las cosas que no encajan, de que no hay quién hable y quién defienda, $\mathrm{y}$ entonces uno se va metiendo desde pequeña y eso como que va llamándole a uno la atención... eran tantas las masacres y los muertos que se tenía que ayudar, pero sobre todo me metí en el cuento de 
este trabajo cuando mataron a mi marido y ahí fue como cuando empezó todo (Fanny. Lideresa Social de mujeres víctimas del conflicto armado. Grupo focal Antioquia).

Y es que las causas sociales de los liderazgos de estas mujeres se encuentran ampliamente vinculadas con los daños sufridos por las comunidades a raíz del conflicto armado, por eso, un tema central en las agendas políticas de las mujeres entrevistadas es abogar e incidir por los derechos de las víctimas. Con este fin, estas mujeres han buscado participar en escenarios como las mesas de participación efectiva de víctimas ${ }^{2}$, mesas de mujeres, consejos de paz y mesas de DDHH en sus territorios. Al respecto, el relato de Lizet:

Luego, el año pasado, en el 2015, vine a formar parte de la mesa. Empezamos a hacer un trabajo arduo ahí, siempre haciendo como esa incidencia en el tema de mujer porque ahí prácticamente... de mujeres nada, ahí es un pueblo muy machista (Lizet. Lideresa asociación de mujeres campesinas. Entrevista Cundinamarca).

Este relato evidencia un factor distintivo de los liderazgos sociales de las mujeres, de hecho, en las mujeres entrevistadas se identifica que una de las causas sociales centrales de su ejercicio es el de abogar por los intereses de las mujeres víctimas, especialmente por quienes han sido víctimas de violencia sexual. Haber sufrido victimizaciones con ocasión del conflicto armado y ser mujer, les posibilita poder escuchar y apoyar a las mujeres que habitan estos territorios, representar a las mujeres en espacios de incidencia política.

Lo anterior es un aporte a la construcción de la paz, puesto que posibilita la transformación de las relaciones de inequidad de género, relaciones de violencias y distintas formas de discriminación contra las mujeres. Tal como se planteó al iniciar el artículo, estas concepciones patriarcales en contextos de conflicto armado generan unos riesgos particulares y unas formas de violencia contra las mujeres, en los cuales se hará enfásis en el apartado siguiente.

Entre tanto, el acompañamiento a las víctimas va más allá de la incidencia que puedan tener estas mujeres en la interlocución con figuras de gobierno o participando en distintos escenarios. Algo que fue evidente en los relatos de las entrevistadas es que los liderazgos contribuyen con la reconstrucción del tejido social que se rompió a causa de la violencia, lo anterior cuando logran escuchar y apoyar la recuperación emocional de quienes han sido víctimas del conflicto armado:

2 Son los escenarios dispuestos desde la Ley de Víctimas y Restitución de Tierras — Ley 1448 de 2011- para que las víctimas del conflicto armado en Colombia puedan participar, hacer veeduría e incidir en la implementación de líneas de acción para la asistencia, atención y reparación integral (Congreso de la República, 2001)
En el sentido de que lo que le sucedió a uno, darle fuerza para ayudar a otras personas a las que le han sucedido cosas, que uno de pronto dice: ¿por qué me pasó esto? Yo voy a ayudar a esa persona porque lo que le pasó... Y quitarnos eso de la cabeza, eso que le hemos quitado a ellas de la cabeza, de que nosotras no somos culpables de lo que nos sucedió, porque nosotros, nunca nadie, quería que eso pasara. Pasó y ya (Angie. Lideresa de mujeres víctimas del conflicto armado. Grupo focal Sucre).

De hecho, podría decirse que una diferencia marcada entre los liderazgos femeninos y los liderazgos masculinos es que las mujeres, desde sus recursos de afrontamiento y el papel histórico del cuidado, han podido acompañar el dolor de las víctimas. Lo hacen cuando escuchan, cuando logran reunir a las comunidades, pero sobretodo, cuando impulsan acciones de visibilización de las situaciones de injusticia, denuncian los hechos de violencia y buscan que se reparen los daños sufridos y se garanticen los derechos a la población. Un ejemplo de ello, el acompañamiento que hace Elena a otras mujeres víctimas del conflicto armado:

A raíz de ese trabajo, de la decisión que yo tomé de meterme en las comunidades, en los barrios, a buscar estas mujeres...y a decirles :"mira, ¿te acuerdas de que yo fui, ya declaraste?", "No, no lo he hecho, me da miedo, estoy amenazada", y yo empiezo y les digo "mira no tengas miedo no vas estar sola, vas estar conmigo, no eres tu sola ya somos nosotras dos y tenemos que hablar porque si nosotras no hablamos nos van a seguir maltratando", es cuando las mujeres empiezan "bueno, sí, yo voy a hablar y tengo otra muchacha en otra parte acá hay otra mujer", y ya las mujeres empezaron a perder el miedo y empezaron a empoderarse ellas mismas. Ellas mismas ya me llamaban, me llaman y me dicen "Elena, mira, tengo una mujer en tal parte para que la conozcas" y así sucesivamente hemos empezado a ayudarnos, y yo pienso que es por eso de que ahorita mismo las mujeres están hablando colectivamente ellas, individualmente con apoyo o sin apoyo ellas están alzando las voces (Elena. Lideresa social de mujeres víctimas del conflicto armado. Entrevista Bogotá D.C.).

En suma, el papel político de las lideresas sociales se construye a partir del conocimiento que tienen estas mujeres de las leyes, de su participación en escenarios de concertación política y de las acciones que desarrollan cotidianamente cuando escuchan a la gente y acompañan el dolor de las víctimas. Esto que hace que las lideresas sociales sean reconocidas en sus regiones como motores de transformación, como voceras ante figuras de gobierno y ante otras figuras de autoridad como los grupos armados ilegales que muchas veces ejercen su poder y hegemonía en estos contextos.

Podría decirse, entonces, que el principal capital político de estas mujeres es la cercanía y las relaciones de confianza 
que tienen con sus comunidades, son actores claves en la instauración de valores democráticos en lugares donde la figura del Estado muchas veces está ausente, especialmente en regiones rurales apartadas del país donde viven y desempeñan el rol las lideresas sociales entrevistadas.

\section{Los riesgos y los intereses políticos detrás de las amenazas y la persecución violenta}

Si las lideresas sociales aportan a la construcción de paz territorial a partir de la difusión de un discurso sobre Derechos Humanos, los ejercicios de participación ciudadana y la denuncia de situaciones de violencia y exclusión social, en ellas reposan unos elementos de poder y legitimidad que en muchos casos se convierten en los argumentos para que actores armados las persigan e intenten silenciar los procesos de movilización y activismo que han emprendido estas mujeres.

En un contexto donde confluyen múltiples intereses económicos y políticos, cuando estas mujeres, en su quehacer de liderazgo y participación, emiten mensajes contradictorios y desafiantes a los intereses hegemónicos de los actores de poder y los grupos armados, se desencadena un escenario de persecución violenta y amenazas con el único fin de amedrentarlas y que desistan de la defensa de los DDHH y de los liderazgos sociales. Por supuesto, esta condición no afecta exclusivamente a las mujeres lideresas, pues los líderes también son perseguidos; lo que se busca evidenciar es que la persecución inicia por la lectura que hacen los actores armados sobre el papel político de las mujeres y el grado de poder que tienen en las decisiones y procesos comunitarios. Esto es evidente en el siguiente testimonio:

Entonces, al uno no querer apoyar esta, cómo le digo, esas propuestas, esas ideologías de ellos, porque pues uno trabaja, uno prácticamente está haciendo el trabajo del Estado, ¿sí? Uno como líder hace el trabajo del Estado, el Estado no está allá pendiente de las comunidades. Uno es el que lleva la problemática al Estado para buscarle una solución. Entonces esto se convierte en, como para ellos, como algo atractivo, ¿sí?, porque dicen "esta persona mueve gente, tiene poder de convencimiento, entonces tenemos que tenerla acá", y si uno no les apoya, pues entonces es cuando ya vienen las amenazas (Lizet. Lideresa asociación de mujeres campesinas. Entrevista Cundinamarca)

James Burns Macgregor, establece que "la reputación es la regla con la que se mide el poder de un líder político" (2010 citado en Barreto, 2017, p. 59). Tal como se dijo, las lideresas gozan de buena reputación entre las comunidades, estas las consultan para tomar decisiones políticas. Lizet, en su entrevista, mencionaba que los grupos armados buscan alianzas con las lideresas como una forma de fortalecer sus intereses y proyectos políticos y económicos en los territorios, pues ellas podrían persuadir a la comunidad para apoyarlos, para que no denuncien las actividades ilegales que se perpetúan en la región o las violencias y victimizaciones.

Cuando líderes y lideresas se niegan o van en contravía de estos proyectos políticos, necesariamente serán perseguidos; no obstante, la persecución y los riesgos tienen una fuerte connotación de género y los intereses detrás de las amenazas hacia lideresas se enmarcan en una cultura patriarcal que no ubica el papel de las mujeres en el ámbito público, en el ámbito de lo político.

Las formas de persecución y los riesgos de género que sufren estas mujeres con ocasión del conflicto armado, responden a las creencias propias de una cultura patriar$\mathrm{cal}$, en la que por medio de la violencia se atenta contra la condición femenina. En esta investigación se identificó que la trayectoria de persecución violenta empieza con las amenazas hacia ellas y sus familias, luego el desplazamiento forzado y en muchos de los casos las trayectorias culminan con la violencia sexual, como una estrategia para violentar a las mujeres, sistemática y generalizada en contextos de conflicto armado. Es el caso de Fanny cuando menciona que una forma de amedrentarla fue atacar su hijo:

Cuando no atacan a la mamá directa atacan a los hijos y en el caso de Adelaida, ella no tuvo lío acá porque tuvo que sacarlos... A mí me dijeron "pilas mujer, van a matar a tu hijo" [...] esos días yo no comía, yo no dormía, y es que yo venía muy mal porque ese día ya iban a matarlo (Fanny. Lideresa Social de mujeres víctimas del conflicto armado. Grupo focal Antioquía).

Por otro lado, se encuentran las amenazas que sufrió Elegida:

muchas de las mujeres que ejercemos liderazgo y la defensa de los derechos humanos y los derechos de las víctimas, muchas, muchas porque sé que somos mayoría las mujeres que somos viudas o madres cabeza de familia, entonces ¿qué pasa? Ellos con la amenaza lo que quieren es callarlo o decirle a uno: "sálgase de eso, quédese quieto, quédese callado" (Elegida. Lideresa de víctimas del conflicto armado. Entrevista Nariño).

Lo anterior implica reconocer que los liderazgos sociales de las mujeres desestabilizan las relaciones de poder y los intereses de los actores armados. Además, teniendo en cuenta que son mujeres desafiando la lógica patriarcal en la que muchas veces la mujer es representada como débil y se considera ilegítima para liderar procesos de activismo político, su rol como lideresas los cuestiona y los afecta, precisamente son mujeres que gozan de prestigio y reputación y movilizan acciones políticas y comunitarias 
en estos territorios. Eneida, en su testimonio, identifica que la persecución hacia las mujeres es mayor por la representación de la mujer en un sistema cultural patriarcal:

Yo pienso que anteriormente, nosotras las mujeres no teníamos voz ni voto, y como ahora nosotras unidas somos más, y ahora las mujeres sabemos cuáles son nuestros derechos y nuestros deberes, entonces por eso la persecución va encaminada a nosotras las mujeres (Eneida. Lideresa comunal. Grupo focal Antioquia).

Lo anterior lleva siempre a la misma pregunta: ¿por qué estas mujeres persisten en sus liderazgos? Precisamente porque en su historia como mujeres víctimas, y ante las múltiples situaciones de injusticia social en la que viven sus comunidades, los liderazgos sociales y la defensa de los DDHH son formas de resistencia, casi que se podría de decir que de afrontamiento hacia las condiciones que sostienen la violencia y la pobreza en Colombia.

\section{Reflexiones finales}

Esto todo comienza por algo: la incidencia política. Yo la entiendo porque hay procesos de participación como el que tuve en un inicio cuando llegué, hice incidencia, me dieron mi casa. Fui la primera mujer escogida en una junta de acción comunal y ahi empecé a hacer incidencia politica desde la comunidad, mi comuna, y luego llegaron las mesas de participación de víctimas, ahi es con propuestas y viendo las necesidades de las víctimas y nuestras necesidades, viendo qué hacía falta para hacer incidencia en las instituciones

Elegida. Lideresa de víctimas del conflicto armado. Entrevista Nariño

Las lideresas sociales como Elegida son mujeres que han desafiado una cultura patriarcal que ha invisibilizado a las mujeres en la esfera política; con su formación sobre Derechos Humanos, el conocimiento que tienen del territorio, pero sobretodo con un recorrido de incidencia y participación, ellas logran abrir nuevos espacios para que las voces y decisiones de las víctimas y las comunidades sean protagonistas en la transformación de las condiciones históricas que han dado lugar al conflicto armado en Colombia y se puedan construir las bases de la Paz territorial desde el saber popular.

Las dieciocho mujeres que participaron en esta investigación son conscientes de los riesgos de ser lideresas defensoras de DDHH y siguen resistiendo la amenaza, la persecución y siguen afrontando el desplazamiento forzado, la violencia sexual y el dolor de ver a muchas de sus compañeras de militancia asesinadas. Las organizaciones sociales de mujeres en el país han venido denunciando desde la década pasada los riesgos y las distintas formas de persecución que día a día sufren las mujeres y que persisten pese a la implementación de los Acuerdos de Paz con las Farc y han desplegado toda una estrategia de incidencia para que desde el Gobierno se formulen soluciones efectivas.

La Corte Constitucional, en el Auto 098 de 2013, insta al Estado colombiano a formular una política pública nacional de garantías para lideresas y defensoras de derechos humanos, que genere líneas de prevención, atención y protección a lideresas sociales con enfoque diferencial y de género. Como una respuesta al mandato de la corte, el Ministerio del Interior, a través del Decreto 1314 del 2016, ordenó la creación de la Comisión Intersectorial de Garantías para las Mujeres Lideresas y Defensoras de los DDHH, la cual se encargue de la formulación de esta política pública; sin embargo, pese a las distintas resoluciones y documentos de política pública, los esfuerzos resultan insuficientes ante las vulneraciones y riesgos que siguen encarando las mujeres.

Es necesario aclarar que en el país no existen sistemas $\mathrm{y}$ registros oficiales frente a las vulneraciones a defensores y defensoras de DDHH, por lo que no es posible establecer con precisión cifras sobre los hechos de violencia que sufren las mujeres lideresas en Colombia. Como referentes para la investigación, se revisaron los documentos del Programa Somos Defensores y de la Oficina del Alto Comisionado de las Naciones Unidas para los Derechos Humanos (Barreto, 2017).

En últimas, la Paz debe conllevar a que desde el Estado se brinden todas las garantías a las comunidades y a los líderes y lideresas que las representan. Como se ha evidenciado, las lideresas sociales representan el sentir de la comunidad, han acompañado el sufrimiento de la guerra y han ayudado a abrir camino para la participación política de las mujeres, cuestionando los dictámenes propios de una cultura patriarcal que se profundiza y exacerba en contextos de conflicto armado, lo que se considera como un aporte significativo e invaluable a la construcción de la paz en los territorios.

\section{Referencias}

Alto Comisionado de las Naciones Unidas para los Derechos Humanos (ACNUDH). (2015). Informe anual del Alto Comisionado de las Naciones Unidas para los Derechos Humanos. Recuperado de http://www.hchr.org.co/documentoseinformes/informes/altocomisionado/A_HRC_28_3__Add_3_SPA.pdf

Alto Comisionado de las Naciones Unidas para los Derechos Humanos (ACNUDH). (2016). Informe del Alto Comisionado de las Naciones Unidas para los Derechos Humanos sobre la situación de los derechos humanos en Colombia. Recuperado de http://www. acnur.org/fileadmin/scripts/doc.php?file=fileadmin/Documentos/BDL/2016/10308

Barreto, S. (2017). Riesgos de los liderazgos sociales de las Mujeres en el contexto del conflicto armado colombiano: configuración de un problema de politica pública. (Tesis de maestría). Bogotá, Universidad Colegio Mayor Nuestra Señora del Rosario. 
Comisión Histórica del Conflicto y sus Víctimas (Ed.). (2015). Contribución al entendimiento del conflicto armado en Colombia. Bogotá: Ediciones Desde Abajo.

Congreso de la República de Colombia. (Junio 10 de 2011). Ley de Víctimas y Restitución de Tierras. [Ley 1448 de 2011]. DO: 48.096.

Coordinación Colombia, Europa, Estados Unidos. (2017). Situación de derechos humanos y derecho humanitario en Colombia 2013-2017. Informe conjunto de organizaciones de derechos humanos para el examen periódico universal de Colombia. Recuperado de https://www. colectivodeabogados.org/IMG/pdf/informe_situacion_derechos_espanol_3_abril_2018.pdf

Corte Constitucional de la República de Colombia. (2008). Auto 092 de 2008, Sentencia T-025 de 2004. Recuperado de http://www. corteconstitucional.gov.co/relatoria/autos/2008/a092-08.htm

Corte Constitucional de la República de Colombia. (2013). Auto 098 de 2013, Sentencia T-025 de 2004. Recuperado de http://www. corteconstitucional.gov.co/relatoria/autos/2013/a098-13.HTM

Crozier, M. y Friedberg, E. (1980). Actors and systems: the politics of collective action. Chicago: University of Chicago Press.

Ministerio del Interior. (2016). Decreto 1314 de 2016. Recuperado de http://es.presidencia.gov.co/normativa/normativa/DECRETO\%201314\%20DEL\%2010\%20DE\%20AGOSTO\%20DE\%20 2016.pdf
Montenegro, M. (2004). La investigación acción participativa. En Introducción a la psicología comunitaria (pp.78-98.). Barcelona: Universitat Oberta de Catalunya.

SISMA Mujer. (2016). Programa de Garantías para Lideresas y defensoras de Derechos Humanos. Recuperado de http://www.sismamujer. org/wp-content/uploads/2016/05/0-4.pdf

Pizarro, E. (2004). Una democracia asediada: balance y perspectivas del conflicto armado en Colombia. Bogotá: Grupo Editorial Norma.

Programa Somos Defensores. (2017). Contra las cuerdas. Informe Anual 2016 Sistema de Información Sobre Agresiones Contra Defensores de DDHH en Colombia SIADDHH. Recuperado de https://somosdefensores.org/attachments/article/144/Contra\%20las $\% 20$ cuerdas.\%20Informe $\% 20$ Anual $\% 20$ Espan $\%$ CC\%83ol\%20220217227p.pdf

Schettini, P. y Cortazzo, I. (2015). Análisis de datos cualitativos en la investigación social. Buenos Aires: Editorial de la Universidad de La Plata.

Semana. (Diciembre 20 de 2017). ONU habla de 105 líderes asesinados y se muestra preocupada por la estigmatización. Revista Semana. Recuperado a partir de http://www.semana.com/nacion/ articulo/lideres-y-defensores-de-derechos-humanos-asesinados-en-colombia-en-el-2017/551193

Torrijos, V. (2009). Gobernabilidad democrática y cohesión de la sociedad. Bogotá: Editorial Universidad del Rosario. 